\title{
Validated RP-HPLC Method for the Determination of Nelaribine in Bulk and Tablet Dosage Form
}

\author{
Prof. D. Chaithanya Sudha \\ A.U. College of Pharmaceutical Sciences, \\ Andhra University, Visakhapatnam, A.P, India
}

\author{
Prof. D. Gowri Sankar \\ A.U. College of Pharmaceutical Sciences, \\ Andhra University, Visakhapatnam, A.P, India
}

\section{ABSTRACT}

A novel, simple and economic reverse phase high performance liquid chromatography (RP-HPLC) method has been developed for the estimation of Nelaribine in bulk and tablet dosage form with greater precision and accuracy. Separation was achieved on Cosmiscil C18 column (150X4.6mm i.d.,5 $\mu \mathrm{m})$ in isocratic mode using Triflouro acetic acid PH-3.6 buffer and Acetonitrile in the ratio of $90: 10(\mathrm{v} / \mathrm{v})$ as mobile phase, pumped in to the column at flow rate of $1.0 \mathrm{~mL}$ min-1and the detection of eluent from the column was carried out using variable wavelength UV detector at $248 \mathrm{~nm}$. The total run time was $15 \mathrm{~min}$ and the column was maintained at ambient temperature. The retention time of Nelaribine was $4.003 \mathrm{~min}$. The standard curves were linear over the concentration range of $25-150 \mu \mathrm{g} / \mathrm{ml}$ with R2 0.999 and the LOD and LOQ values for Nelaribine were $0.04 \mu \mathrm{g} / \mathrm{ml}$ and $0.12 \mu \mathrm{g} / \mathrm{ml}$, respectively. The percentage recovery was found to be $101.76-98.72 \%$, the \% RSD was found to be 0.43 . The percentage amount of a marketed tablet formulation of Nelaribine was found to be $101.2 \%$. The method was validated as per ICH guidelines. Validation studies demonstrated that the proposed RP-HPLC method is simple, specific, rapid, reliable and reproducible. Hence the proposed method can be applied for the routine quality control analysis of Nelaribine in bulk and tablet dosage forms.

KEYWORDS: Nelaribine, RP-HPLC, Method Development, Validation, ICH guidelines

\section{INTRODUCTION}

NELARABINE is a purine nucleoside analog converted to its corresponding arbinosylguanine nucleoside tri phosphate results inhibition of DNA synthesis and cytotoxicity. The drug is ultimately metabolized into the active 51-tri phosphate ara-GTP which disrupts the DNA synthesis and induces apoptosis. Nelarabine is used to treat T-cell acute Lymphoblastic leukemia and T-cell lymphoblastic lymphoma. The Chemical name of Nelaribine (2R,3S,4S,5R)-2-(2-amino-6-methoxy-9H-purin-9yl)-5 -(hydroxymethyl) oxolane-3,4-diol and chemical formula is $\mathrm{C} 10 \mathrm{H} 11 \mathrm{ClFN} 5 \mathrm{O} 3$ and molecular weight is $297.27 \mathrm{~g} / \mathrm{mol}$.

\section{MATERIALS AND METHODS}

\section{Chemicals and solvents}

The reference sample of NELARABINE was supplied by M/s Natco laboratories,Hyd. The Branded formulations of NELARABINE (Arranon Vials; Glaxosmithkline) were purchased from the local market. Ortho phosphoric acid, Acetonitrile, and water used are of HPLC grade.

\section{Instrumentation}

A Aliance waters (2487) HPLC instrument, equipped

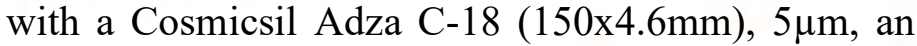
LC 20 AD pump and a SPD 20AD UV-Visible detector was employed in this study. Chromatographic analysis and data acquisition was monitored by using empower-2software. A $20 \mu \mathrm{L}$ Hamilton injection syringe was employed for sample injection. Degassing of the mobile phase was done by using a SV scientific ultrasonic sonicator. A Mettle Toledo AL 104 electronic balance was used for weighing the materials. Class ' $A$ ' Borosil glass ware (Borosil, India) was employed for volumetric and general purpose in the entire study.

\section{Chromatographic Conditions}

The mobile phase consists of $\mathrm{PH} 3.6$ buffer : Acetonitrile in the ratio of $90: 10 \mathrm{v} / \mathrm{v} \%$. The mobile phase was pumped from solvent reservoir in the ratio of $90: 10 \% \mathrm{v} / \mathrm{v}$ to the column in the flow rate of 1.0 $\mathrm{ml} / \mathrm{min}$ whereas run time set was $15 \mathrm{~min}$. The separation was performed on Cosmicsil C18 column 
and the column was maintained the temperature of $25^{\circ} \mathrm{C}$ and the volume of each injection was $10 \mu \mathrm{L}$. Prior to injection, the column was equilibrated for at least 30 min with mobile phase flowing through the system. The eluents were monitored at $248 \mathrm{~nm}$.

\section{Preparation of buffer solution: (PH: 3.6):}

$1 \mathrm{ml}$ of Trifloroacetic acid solution in a $1000 \mathrm{ml}$ of volumetric flask add about $100 \mathrm{ml}$ of milli-Q water and final volume make up to $1000 \mathrm{ml}$ with milli-Q water and degas to sonicate and finally make up the volume with water then added $1 \mathrm{ml}$ of Triethylamine then $\mathrm{pH}$ adjusted to 3.6 with dil. Trifloroacetic acid solution.

\section{Preparation of mobile phase:}

Buffer and Acetonitrile are in the ratio 90:10 \%v/v, filtered through $0.45 \mu$ filter under vacuum.

\section{Preparation of standard solution: $(100 \mu \mathrm{g} / \mathrm{ml})$ :}

Accurately Weigh and transfer accurately $31.25 \mathrm{mg}$ of Nelarabine working Standard into a $50 \mathrm{ml}$ clean dry volumetric flask, and add about $30 \mathrm{ml}$ of diluents, dissolve and dilute to volume with diluents. Transfer $2.0 \mathrm{ml}$ above solution into $200 \mathrm{ml}$ volumetric flask and dilute to volume with diluent( Milli-Q water as diluent).

\section{Preparation of sample solution:}

Accurately pipette out $2.0 \mathrm{ml}$ of sample solution in to $200 \mathrm{~mL}$ volumetric flask without any loss of solution. Add $120 \mathrm{ml}$ of diluent, shake well to dissolve and dilute to volume with diluents and mix well. From the filtered solution $1 \mathrm{ml}$ was pipette out into a $10 \mathrm{ml}$ volumetric flask and made up to $10 \mathrm{ml}$ with diluent.

Label Claim: $37.5 \mathrm{mg}$ of Nelaribine

\section{Validation of Proposed method:}

The developed method was validated as per the $\mathrm{ICH}$ (International Conference on Harmonization) guidelines with respect to System suitability, Precision, Specificity, Forced degradation studies, Linearity, Accuracy, Limit of detection and Limit of quantification.

\section{Linearity}

Aliquots of $0.25,0.5,0.75,1.0,1.25$ and $1.5 \mathrm{ml}$ were taken from stock solution of concentration $100 \mu \mathrm{g} / \mathrm{ml}$ of Nelaribine and then diluted up to mark with diluent. Such that the final concentrations were in the range 25-150 ppm of Nelaribine. Volume of $10 \mu 1$ of each sample was injected in five times for each concentration level and calibration curve was constructed by plotting the peak area versus drug concentration. A linear relationship between peakarea vs. concentration was observed in the range of study. The observations and calibration curve were shown in figure.2.

\section{Linearity and Construction of calibration curve}

The quantitative determination of the drug was accomplished by the external standard method. The mobile phase was filtered through a $0.45 \mu$ membrane filter before use. The flow rate of the mobile phase was adjusted to $1.0 \mathrm{~mL} / \mathrm{min}$. The column was equilibrated with the mobile phase for at least $30 \mathrm{~min}$ prior to the injection of the drug solution. The column temperature is maintained at $25 \pm 10 \mathrm{C}$ throughout the study. Linearity of the peak area response was determined by taking six replicate measurements at seven concentration points. Working dilutions of NELARABINE in the range of $25-150 \mu \mathrm{g} / \mathrm{mL}$ were prepared by taking suitable dilutions of the standard solutions in different $10 \mathrm{~mL}$ volumetric flasks and diluted up to the mark with the mobile phase. Twenty microlitres of the dilutions was injected each time into the column at flow rate of $1.0 \mathrm{~mL} / \mathrm{min}$. Each dilution was injected six times into the column. The drug in the eluents was monitored at $248 \mathrm{~nm}$ and the corresponding chromatograms were obtained. From the chromatograms, the mean peak areas were noted and a plot of concentrations over the peak areas was constructed. The regression of the plot was computed by least squares method. The linear relationship was found to be in the range of $25-150 \mu \mathrm{g} / \mathrm{mL}$ between the concentration of NELARABINE and peak area response. This regression equation was later used to estimate the amount of NELARABINE in pharmaceutical dosage forms. The linearity plot was shown in the Fig.2 and the linearity data and the statistical parameters for the linearity plot are reported in Table $3 \& 4$.

\section{VALIDATION OF THE PROPOSED METHOD:}

The method was validated in compliance with $\mathrm{ICH}$ guidelines. The following parameters were determined for validation. 


\section{Specificity}

The method specificity was assessed by comparing the chromatograms obtained from the drug with the most commonly used excipient mixture with those obtained from the blank solution. The blank solution was prepared by mixing the excipients in the mobile phase without the drug. The drug to excipient ratio used was similar to that in the commercial formulations. The commonly used excipients in formulations like lactose, starch, microcrystalline cellulose, ethyl cellulose, hydroxyl propyl methylcellulose, magnesium stearate and colloidal silicon dioxide were used for the study. The mixtures were filtered through $0.45 \mu$ membrane filter before injection. An observation of the chromatograms indicates absence of excipient peaks near the drug peak in the study runtime. This indicates that the method is specific.

\section{Precision}

Precision is the degree of repeatability of an analytical method under normal operational conditions. The precision of the method was studied in terms of repeatability (intra-day assay) and intermediate precision (inter-day assay). Method repeatability was studied by repeating the assay three times in the same day for intra-day precision and intermediate precision was studied by repeating the assay on three different days, three times on each day (inter-day precision). The intra-day and inter-day variation for determination of NELARABINE was carried out at three different concentration levels $25,50,75 \mu \mathrm{g} / \mathrm{mL}$ level. The coefficient of variation values as presented in the Table.5 shows that the method provides acceptable $(<2)$ intraday and inter-day variation.

\section{Accuracy}

Accuracy of the method was evaluated by standard addition method. An amount of the pure drug at three different concentration levels in its solution has been added to the pre analysed working standard solution of the drug. The sample solutions were analysed in triplicate at each level as per the proposed method. The percent individual recovery and \%RSD for recovery at each level are calculated. The results are tabulated (Table.6). A recovery ranged from 98.72 $102 \%$ has been obtained by the method indicates its accuracy.

\section{Robustness}

A study was conducted to determine the effect of deliberate variations in the optimized chromatographic conditions like composition of the mobile phase, flow rate, and mobile phase $\mathrm{pH}$. The effect of these changes on the system suitability parameters like tailing factor and number of theoretical plates and on assay was studied. A single condition was varied at a time keeping all other parameters constant. The results were found to be within the allowed limits which indicate that the method is specific.

\section{Variations in flow rate of the mobile phase:}

Demonstrated robustness of method by changing the flow rate for $0.9 \mathrm{ml} / \mathrm{min}$ and $1.1 \mathrm{ml} / \mathrm{min}$ instead of specified flow rate $(1.0 \mathrm{ml} / \mathrm{min})$. By injecting the replicate injections of standard in $0.9 \mathrm{ml} / \mathrm{min}$ and 1.1 $\mathrm{ml} / \mathrm{min}$ flow rate and found that system suitability parameters were passed. The \%RSD of peak area, tailing factor and theoretical plates of Nelarabine standard was found within the limits.

\section{Variations in the pH of the mobile phase:}

The effect of variation in the $\mathrm{pH}$ of the mobile phase was evaluated at \pm 0.2 levels. The system suitability results were found to be within the limits as shown in the following table-

\section{Variations in the temperature of column:}

Robustness of the method by changing the column temperature for $28^{\circ} \mathrm{C}$ and $31^{\circ} \mathrm{C}$ instead of specified column temperature $\left(30^{\circ} \mathrm{C}\right)$ are shown. By injecting the replicate injections of standard in $28^{\circ} \mathrm{C}$ column and $31^{\circ} \mathrm{C}$ column temperature and found that system suitability parameters were passed. The \%RSD of peak area, tailing factor and theoretical plates of Nelarabine standard was found within the limits.

\section{Limit of Detection and Limit of Quantification}

Limit of detection (LOD) is defined as the lowest concentration of analyte that gives a measurable response. LOD is determined based on signal to noise ratio $(\mathrm{S} / \mathrm{N})$ of three times typically for HPLC methods. The limit of quantification (LOQ) is defined as the lowest concentration that can be quantified reliably with a specified level of accuracy and precision. It is the lowest concentration at which the 
precision expressed by a RSD of less than $2 \%$. In this study the analyte response is 10 times greater than the noise response. For this study six replicates of the analyte at lowest concentration in the calibration range were measured and quantified.

Average Baseline Noise obtained from Blank = $98.1936 \mu \mathrm{V}$

Signal Obtained from LOD solution $=7985 \mu \mathrm{V}$

$$
\begin{aligned}
\mathbf{L O D} & =3.3 \times \sigma / \mathbf{s} \\
& =3.3 \times 98.1936 / 7985 \\
& =0.0405
\end{aligned}
$$

$$
\begin{aligned}
\mathbf{L O Q} & =10 \times \sigma / \mathrm{s} \\
& =10 \times 98.1936 / 7985 \\
& =0.1229
\end{aligned}
$$

\section{System precision and System suitability}

System precision and system suitability studies were carried out by injecting six replicates of the working standard solution. The \% RSD for the peak areas obtained was calculated. The data presented in Table 2.3.9 $\quad(\% \quad \mathrm{RSD}<1) \quad$ establishes reproducible performance of the instrument. The system suitability parameters are given in Table 2.3.10.

\section{Assay calculation:}

$\%$ Assay $=\frac{T A}{S A} \times \frac{S W}{100} \times \frac{5}{50} \times \frac{100}{2} \times \frac{P}{100} \times \frac{100}{L . A}$

Where,

$\mathrm{TA}=$ peak area response due to Nelarabine from sample

$\mathrm{SA}=$ peak area response due to Nelarabine from standard

$\mathrm{SW}=$ Weight of Nelarabine working standard taken in $\mathrm{mg}$

$\mathrm{P}=$ purity of Nelarabine working standard taken on as is basis

L.A = Labeled amount of Nelarabine in $\mathrm{mg}$ $\%$ Assay

$862111 / 845634 \times 31.25 \times 2 / 25 \times 200 / 2 \times 99.2 / 100 \times 100 / 5$

$=100.192 \%$

\section{CONCLUSION}

The present study was aimed at developing a sensitive, precise and accurate HPLC method for the analysis of NELARABINE in bulk drug and in pharmaceutical dosage forms. using C18 column, flow rate was $1.0 \mathrm{ml} / \mathrm{min}$, mobile Phase: Trifluoroacetic acid buffer solution $\mathrm{pH} 3.6 \pm 0.05$ and solvent mixture (Acetonitrile) in $(90: 10 \mathrm{v} / \mathrm{v})$. Detection wave length was $248 \mathrm{~nm}$. The instrument used was WATERS HPLC auto sampler. The retention times were found to be 4.003 mins. The analytical method was validated according to $\mathrm{ICH}$ guidelines (ICH Q2b). The correlation coefficient (r2) was found to be $0.998, \%$ recovery was 101.76 $98.72 \%$ and $\% \mathrm{RSD}$ for precision on replicate injection was 0.43 and intermediate precision for intraday precision at condition- I, II and III was $0.7,0.2$ and 0.3 interday precision at condition-I,II and III was $1.2,0.3$ and 0.3 respectively. The precision study was precise, robust, and repeatable. LOD value was 0.0405 and LOQ value was 0.1229.

The deliberate changes in the method have not much affected the peak tailing, theoretical plates and the percent assay. This indicates that the present method is robust. The lowest values of LOD and LOQ as obtained by the proposed method indicate the method is sensitive. The standard solution of the drug was stable up to 24 hours as the difference in percent assay is within limit.

System suitability parameters were studied with six replicates standard solution of the drug and the calculated parameters are within the acceptance criteria.

The tailing factor, the number theoretical plates and HETP are in the acceptable limits. Hence the author concludes that the proposed HPLC method is sensitive and reproducible for the analysis of NELARABINE in pharmaceutical dosage forms with short analysis time.

\section{REFERENCES}

1) Nelarabineinjection drug profile and pharmaco kinetic information, from website http://www.drug information.com/RxDrugs/N/Nelarabine

Injection.htm accessedon 08/01/2013.

2) Jeanette Kaiser, PharmD, Professor Irene Krämer, "Physico-chemical stability of nelarabine infusion 
solutions in EVA infusion bags", European Journal Hospital Pharma Science, 2011, Vol; 17(1), P.7-12.

3) Suresh Kumar GV, Rajendraprasad Y, Development and Validation of Reversed-Phase HPLC Method for Simultaneous Estimation of Rosuvastatin and Fenofibrate in Tablet Dosage Form, International Journal of Pharm Techniques Research, (2010),Vol ;2(3),P.206-202.

4) Jan Styczynski, Beata Kolodziej, Beata Rafinska, Differential activity of nelarabine a clofarabine in leukaemia and lymphoma cell lines, Wspolczesna Onkologia, (2009) Vol; 13(6),P.281-286.

5) Wang Juan, Zhang Rong, ZHAO Yan-yan, Lu Lai-Chun, High-performance liquid chromatography Clofarabine Clofarabine Injection content ,(2009),Vol;18,P. 8-24.

6) Peter L. Bonateet al, The distribution, metabolism, and elimination of Clofarabine in rats, $\mathrm{J}$ Oncol Pharm Pract, ( 2005),Vol; 33( 6), P.739-748.

7) Kurtzberg J, Ernst TJ, Keating MJ, Gandhi V, Hodge JP, Kisor DF, Lager JJ, Stephens C, Levin J, Krenitsky T, Elion G, Mitchell BS. Phase I administered on a consecutive 5-day schedule in children and adults with refractory hematologic malignancies. Journal of Clinical Oncology (2005), Vol; 23(15),P.3396-3403.

8) Berg SL, Blaney SM, Devidas M, Lampkin TA, Murgo A, Bernstein M, Billett A, Kurtzberg J, Reaman G, Gaynon P, Whitlock J, Krailo M, Harris MB, Phase II study of nelarabine in children and young adults with refractory T-cell malignancies, Journal of Clinical Oncology (2005) ,Vol ;23(15), P.3376-3382.

9) Parker WB, Secrist JA 3rd, Waud WR, Purine nucleoside antimetabolites in development for the treatment of cancer. Current Opinion in Investigational Drugs (2004), Vol; 5(6), P.592596.

10) B.k Sharma, instrumental methods of chemical analysis, introduction to analytical chemistry, 19th ed, goel publishing house , meerut, (2004), P.286385.

11) Gurdeep R. Chatwal, Sharma K and Anand, Instrumental Method of Chemical analysis, 5th Edition, Himalaya publication, New Delhi ,(2008),P.561-567.

12) International Conference on Harmonization (ICH) Harmonised Tripartite Guideline, Validation of Analytical Procedures, Text and Methodology, (2005), Q2 (R1).
13) Michael E, Schartz IS, Krull. Analytical method development and Validation, 3rd ed. John Wiley \& sons, London,( 2004),P. 25-46.

14) Douglas A Skoog, Donald M west, James Holler F, Fundamentals of analytical chemistry 7th edition, (2004), Vol; 1(13),P. 628-641.

15) Frank A settle, hand book of instrumental techniques for analytical chemistry, Pearson edition, (2004), P.147-159.

16) PD Sethi. High performance liquid chromatography,1sted, CBS Publishers \& Distributers, New Delhi, (2001),P.1-30.

17) David G. Watson, Pharmaceutical Analysis, 1st edition, Churchill Livingstone, Harcourt Publishers limited, (1999).

18) Beckett A.H and J.B. Stenlake, Practical Pharmaceutical Chemistry, CBS Publishers and Distributers; volume II, (1997), P. 157-160.

19) Chasten LG. Pharmaceutical Chemistry. Vol. II. New York: Marcel Dekker Inc; 1996, P. 23-25.

20) International conference of Harmonization Guidelines on validation of Analytical Procedures Definitions and Terminology Federal Register, (1995).

21) Lough WJ, Wainer IW. High Performance Liquid Chromatography: fundamental principles \& practice. Glasgow (UK): Blackie Academic \& Professional, (1995), P. 2-28.

22) Asian Guideline for Validation of Analytical Procedure Adopted from ICH guideline, Q2A27 (1994) and ICH Q2B, (1994).

23) David CL, Michael Webb. Pharmaceutical Analysis. London: Black well publishing, (1994), P.2-4.

24) $\mathrm{ICH}$, Stability testing of new drug substances and products. Geneva: International Conference on Harmonization. IFPMA,2003.

25) Mallikarjunarao B, Arpita C, Srinivasu MK, Lalithadevi M, Rajender kumar P, Chandrasekhar KB, Srinivasan AK, Prasad AS and Ramanatham $\mathrm{J}$, A stability indicating HPLC assay method for docetaxel. J Pharm and BiomedAnal. 2006; 41: 676-681.

26) Stokvis E, Rosing H, Beijen JH. Liquid chromatography-mass spectrometry for the quantitative analysis of anticancer drugs. Mass Spectrom Rev2005;24:887-917. 
Figures:

\section{Chemical Structure:}

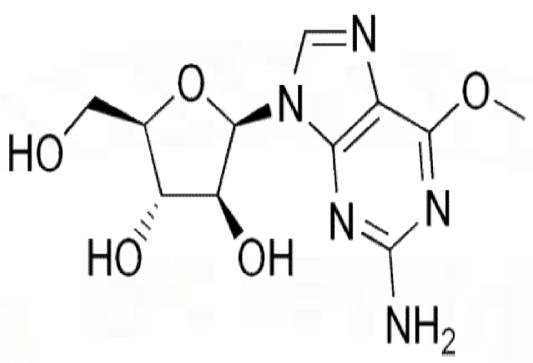

Figure.1

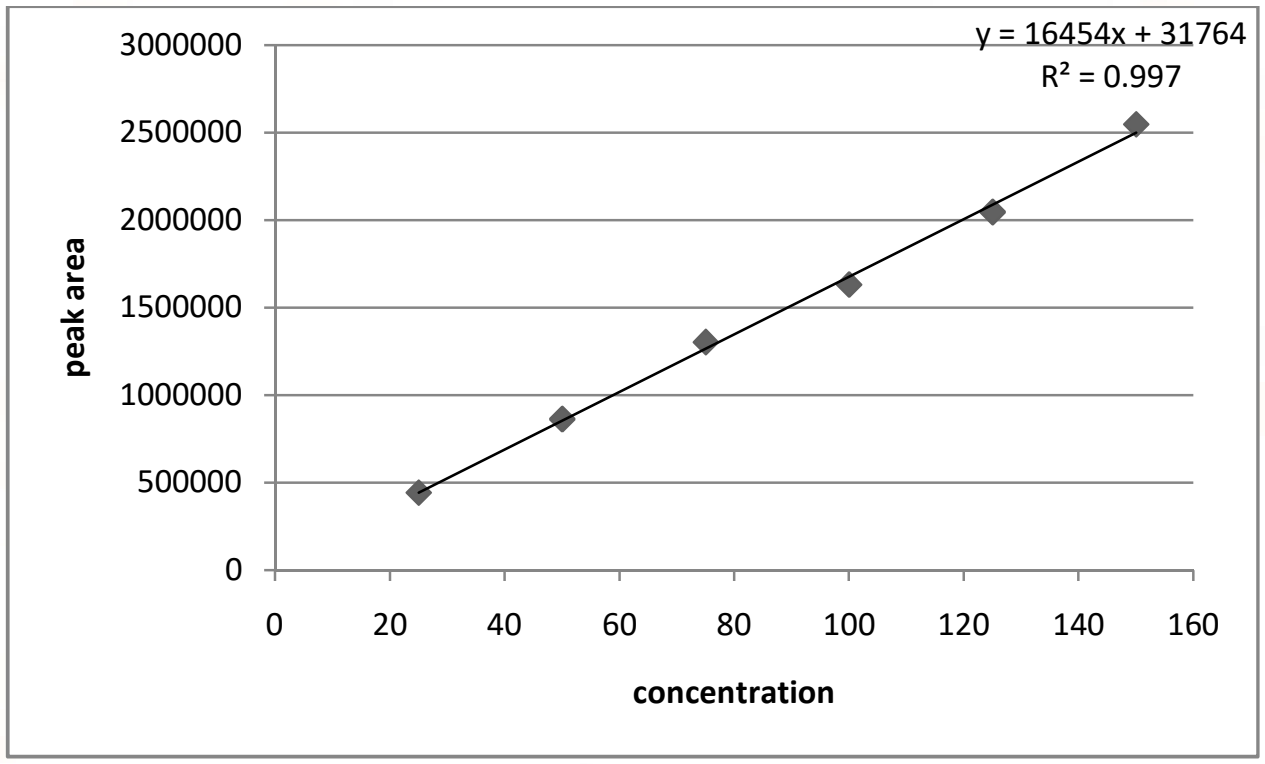

Fig.2 Linearity Plot for the proposed method

Table 1 Optimized Chromatographic conditions and system suitability parameters for proposed HPLC method for Nelaribine

Parameter Chromatographic conditions

\begin{tabular}{|c|c|c|}
\hline S.No & Parameter & Value \\
\hline $\mathbf{1}$ & Column & $\begin{array}{r}\text { Cosmicsil Adza C-18 } \\
(150 \mathrm{x} 4.6 \mathrm{~mm}), 5 \mu \mathrm{m}\end{array}$ \\
\hline $\mathbf{2}$ & Mobile phase & $\begin{array}{r}\text { Trifluoro acetic acid } \mathrm{pH}-3.6 \\
\text { buffer and Acetonitrile in the } \\
\text { ratio of } 90: 10 \mathrm{v} / \mathrm{v}\end{array}$ \\
\hline $\mathbf{3}$ & Flow rate & $1 \mathrm{~mL} / \mathrm{min}$ \\
\hline $\mathbf{4}$ & Run time & $15.0 \mathrm{~min}$ \\
\hline $\mathbf{5}$ & Column temperature & $25 \pm 1^{0} \mathrm{C}$ \\
\hline
\end{tabular}




\begin{tabular}{|c|c|c|}
\hline $\mathbf{6}$ & Volume of injection & $10 \mu \mathrm{L}$ \\
\hline $\mathbf{7}$ & Detection wave length & $248 \mathrm{~nm}$ \\
\hline $\mathbf{8}$ & Retention time of the drug & $4.003 \mathrm{~min}$ \\
\hline
\end{tabular}

Table.2 Accuracy

\begin{tabular}{|c|c|c|}
\hline S.NO & $\begin{array}{c}\text { Conc. Of } \\
\text { Nelarabine in } \\
\text { ppm }\end{array}$ & $\begin{array}{c}\text { Nelarabine } \\
\text { peakArea }\end{array}$ \\
\hline $\mathbf{1}$ & 25 & 442399 \\
\hline $\mathbf{2}$ & 50 & 862111 \\
\hline $\mathbf{3}$ & 75 & 130223 \\
\hline $\mathbf{4}$ & 100 & 1630614 \\
\hline $\mathbf{5}$ & 125 & 2045323 \\
\hline $\mathbf{6}$ & 150 & 2512346 \\
\hline
\end{tabular}

Table.3 Calibration of the proposed HPLC Method

\begin{tabular}{|c|c|}
\hline $\begin{array}{c}\text { Concentration of } \\
\text { NELARABINE }(\mu \mathrm{\mu g} / \mathrm{mL})\end{array}$ & Peak Area \\
\hline 25 & 442399 \\
\hline 50 & 862111 \\
\hline 75 & 1302223 \\
\hline 100 & 1630614 \\
\hline 125 & 2045323 \\
\hline 150 & 2546233 \\
\hline
\end{tabular}

Table.4 Regression characteristics of the linearity plot of NELARABINE

\begin{tabular}{|c|c|}
\hline Parameter & Value \\
\hline Linearity Range $(\mu \mathrm{g})$ & $25-150$ \\
\hline Slope (a) & 16264 \\
\hline Intercept (b) & 30585 \\
\hline
\end{tabular}




\begin{tabular}{|c|c|}
\hline Correlation coefficient & 0.998 \\
\hline Regression Equation & $Y=16264 X+30585$ \\
\hline
\end{tabular}

Table.5. Precision of the proposed method

\begin{tabular}{|c|c|c|c|c|c|c|}
\hline $\begin{array}{c}\text { Concentration } \\
\text { of } \\
\text { NELARABINE } \\
(\mu \mathrm{g} / \mathrm{mL})\end{array}$ & \multicolumn{3}{|c|}{ Intra-day Precision } & \multicolumn{3}{c|}{ Inter-day Precision } \\
\cline { 2 - 7 } & Mean & SD & \% RSD & $\begin{array}{c}\text { Mean } \\
\text { amount } \\
\text { found } \\
(\mathbf{n = 9})\end{array}$ & SD & $\%$ RSD \\
\hline $\mathbf{2 5}$ & 445202 & 3132.96 & $0.7 \%$ & 448172 & 8624.2 & $1.2 \%$ \\
\hline $\mathbf{5 0}$ & 860569 & 1947.16 & $0.2 \%$ & 858664 & 2784.8 & $0.3 \%$ \\
\hline $\mathbf{7 5}$ & 1356106 & 4428.01 & $0.3 \%$ & 1304275 & 4832.2 & $0.3 \%$ \\
\hline
\end{tabular}

Table.6 Accuracy data (Triplicate values at different concentration levels)

\begin{tabular}{|c|c|c|c|c|c|}
\hline \multirow[t]{2}{*}{$\begin{array}{l}\text { Spike } \\
\text { Level }\end{array}$} & Conc $\mu \mathrm{g} / \mathrm{m}$ & Conc $\mu \mathrm{g} / \mathrm{ml}$ & Amount found & $\begin{array}{c}\% \\
\text { Recovery }\end{array}$ & \multirow[t]{2}{*}{$\begin{array}{l}\text { Mean \% } \\
\text { Recovery }\end{array}$} \\
\hline & Amount added (pure) & $\begin{array}{l}\text { Amount added } \\
\text { (formulation) }\end{array}$ & & & \\
\hline \multirow[t]{3}{*}{$80 \%$} & 8 & 10 & 7.864 & 101.84 & \multirow{3}{*}{101.76} \\
\hline & 8 & 10 & 7.872 & 101.72 & \\
\hline & 8 & 10 & 7.863 & 101.73 & \\
\hline \multirow[t]{3}{*}{$100 \%$} & 10 & 10 & 10.022 & 99.64 & \multirow{3}{*}{99.35} \\
\hline & 10 & 10 & 10.030 & 99.77 & \\
\hline & 10 & 10 & 10.024 & 99.72 & \\
\hline \multirow[t]{3}{*}{$120 \%$} & 12 & 10 & 12.156 & 98.65 & \multirow{3}{*}{98.72} \\
\hline & 12 & 10 & 12.147 & 98.81 & \\
\hline & 12 & 10 & 12.176 & 98.70 & \\
\hline
\end{tabular}


Table.7

\begin{tabular}{|c|c|c|c|}
\hline $\begin{array}{c}\text { Variations in the } \\
\text { flow rate }\end{array}$ & Peak area & Average & \% RSD \\
\hline \multirow{2}{*}{$\mathbf{0 . 9} \mathbf{m l} / \mathbf{m i n}$} & 864511 & \multirow{2}{*}{866702} & \multirow{2}{*}{$0.2 \%$} \\
\cline { 2 - 2 } & 867732 & & \\
\cline { 2 - 2 } & 867865 & \multirow{2}{*}{867083} & $0.1 \%$ \\
\cline { 2 - 2 } $\mathbf{4} \mathbf{1 . 1} \mathbf{m l} / \mathbf{m i n}$ & 865567 & & \\
\cline { 2 - 2 } & 867783 & & \\
\hline
\end{tabular}

Table.8

\begin{tabular}{|c|c|c|c|}
\hline Variations in the & Peak area & Average & $\%$ RSD \\
\hline \multirow{3}{*}{3.4} & 865577 & \multirow{3}{*}{867451} & \multirow{3}{*}{$0.1 \%$} \\
\hline & 867883 & & \\
\hline & 868894 & & \\
\hline \multirow{3}{*}{3.8} & 866221 & \multirow{3}{*}{867297} & \multirow{3}{*}{$0.1 \%$} \\
\hline & 867783 & & \\
\hline & 867889 & & \\
\hline
\end{tabular}

Table.9

\begin{tabular}{|c|c|c|c|}
\hline $\begin{array}{c}\text { Variations in the } \\
\text { temperature }\end{array}$ & Peak area & Average & \% RSD \\
\hline \multirow{2}{*}{$\mathbf{2 8}^{\mathbf{0}} \mathbf{c}$} & 588678 & \multirow{2}{*}{588780} & \multirow{2}{*}{$0.018 \%$} \\
\cline { 2 - 2 } & 588772 & & \\
\cline { 2 - 2 } & 588892 & & \multirow{2}{*}{867509} \\
\cline { 2 - 2 } $\mathbf{3 1}^{\mathbf{0}} \mathbf{c}$ & 867745 & & $0.07 \%$ \\
\cline { 2 - 2 } & 866785 & & \\
\hline
\end{tabular}

Table.10 System precision

\begin{tabular}{|c|c|}
\hline Injection No. & Peak area \\
\hline 1 & 845634 \\
\hline 2 & 857096 \\
\hline 3 & 866190 \\
\hline 4 & 853829 \\
\hline 5 & 850789 \\
\hline 6 & 859723 \\
\hline
\end{tabular}




\begin{tabular}{|c|c|}
\hline Mean & 855543 \\
\hline SD & 7138.6 \\
\hline \% RSD & $0.8 \%$ \\
\hline
\end{tabular}

Table.11 System suitability parameters

\begin{tabular}{|l|c|}
\hline \multicolumn{1}{|c|}{ Parameters } & Values \\
\hline Theoretical plates (n) & 4890 \\
\hline Plates per meter (N) & 7509 \\
\hline Tailing factor (T) & 1.08 \\
\hline LOD & 0.0405 \\
\hline LOQ & 0.1229 \\
\hline
\end{tabular}

